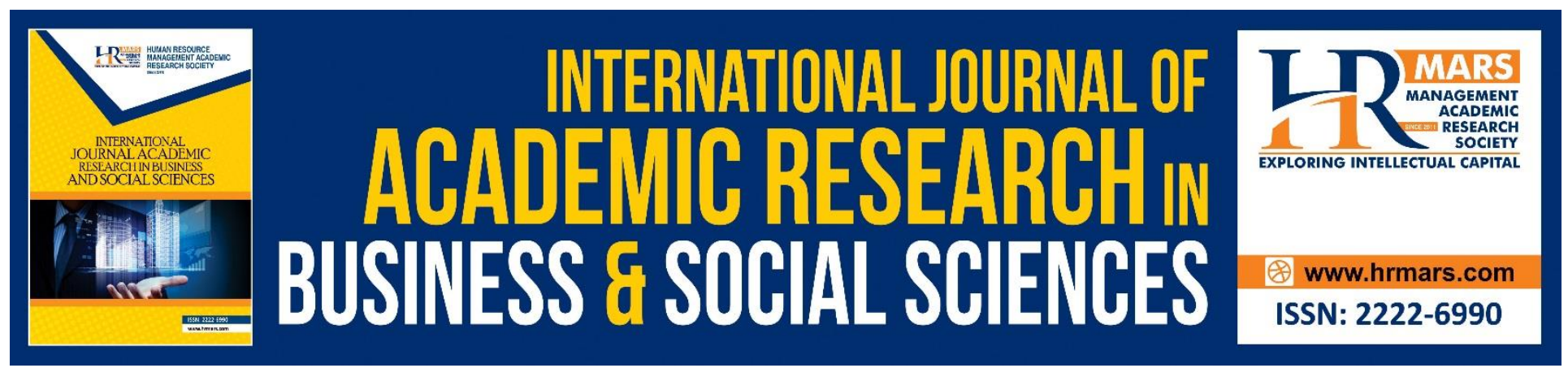

\title{
The Importance of Friends' and Family Members' Influence and Subjective Norm in Propelling Individual's Intention to Purchase Halal Personal Care Products
}

Sulaiman Bin Nawawi, Rosmimah Bt Mohd Roslin, Norlida Bt Abdul Hamid

To Link this Article: http://dx.doi.org/10.6007/IJARBSS/v8-i11/5565

DOI: $10.6007 /$ IJARBSS/v8-i11/5565

Received: 29 Oct 2018, Revised: 23 Nov 2018, Accepted: 10 Dec 2018

Published Online: 11 Dec 2018

In-Text Citation: (Nawawi, Roslin, \& Hamid, 2018)

To Cite this Article: Nawawi, S. Bin, Roslin, R. B. M., \& Hamid, N. B. A. (2018). The Importance of Friends' and Family Members' Influence and Subjective Norm in Propelling Individual's Intention to Purchase Halal Personal Care Products. International Journal of Academic Research in Business and Social Sciences, 8(11), 2017-2028.

Copyright: (C) 2018 The Author(s)

Published by Human Resource Management Academic Research Society (www.hrmars.com)

This article is published under the Creative Commons Attribution (CC BY 4.0) license. Anyone may reproduce, distribute, translate and create derivative works of this article (for both commercial and non-commercial purposes), subject to full attribution to the original publication and authors. The full terms of this license may be seen

at: http://creativecommons.org/licences/by/4.0/legalcode

Vol. 8, No. 11, 2018, Pg. 2017 - 2028 


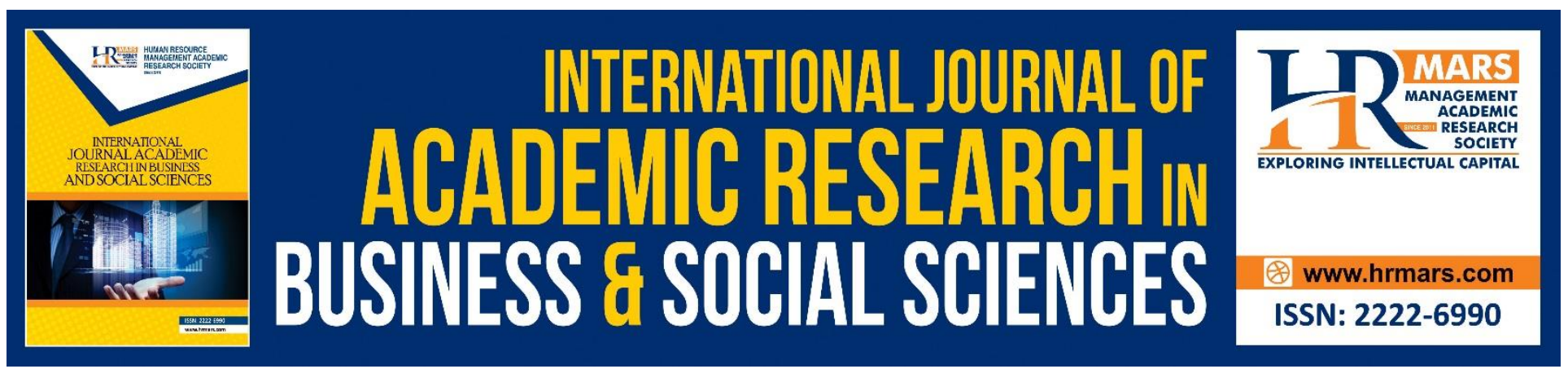

\title{
The Importance of Friends' and Family Members' Influence and Subjective Norm in Propelling Individual's Intention to Purchase Halal Personal Care Products
}

\author{
Sulaiman Bin Nawawi ${ }^{1}$, Rosmimah Bt Mohd Roslin², \\ Norlida Bt Abdul Hamid ${ }^{3}$ \\ ${ }^{1}$ Universiti Teknologi MARA (UTTM), Department of Marketing, Faculty of Business Management, \\ Shah Alam, Malaysia. \\ ${ }^{2}$ Professor, Universiti Teknologi MARA (UiTM), Department of Marketing, Faculty of Business \\ Management, Shah Alam, Malaysia \\ ${ }^{3}$ Associate Professor, Universiti Teknologi MARA (UiTM), Department of Marketing, Faculty of \\ Business Management, Shah Alam, Malaysia
}

\begin{abstract}
Background: This paper further extends the purchase intention study on halal personal care product by applying the decomposed theory of planned behavior (DTPB), thus, providing significant contribution to the body of knowledge and literatures on halal non-food study. Objective: The main objective of the paper is to investigate the effect of friends' influence, family members' influence and subjective norm in influencing individual's intention to purchase halal personal care products. Methodology: Data were collected from 405 Muslim respondents in Klang Valley, Malaysia, using a combination of purposive and quota sampling approach. The data were later analyzed using the Statistical Package for Social Sciences (SPSS) and Partial Least Square - Structural Equation Modeling (PLS SEM) Results: The results revealed that friends' influence and family members' influence were significant determinant of subjective norm. In addition, it was found that subjective norm had a significant positive influence on one's intention to purchase halal personal care products. Conclusion: By examining friends' influence, family members' influence, and subjective norm, the study validated the importance of these three constructs in affecting one's behavioral intention towards halal personal care products. In addition, this study would be useful for marketers, manufacturers, and product managers as the findings would help them formulate and pursue relevant marketing strategies for their companies' promotional activities.

Keywords: Friends' influence, family members' influence, subjective norm, intention to purchase, halal personal care products, Decomposed Theory of Planned Behavior (DTPB)
\end{abstract}




\section{INTRODUCTION}

Halal personal care product industry has turned out to be one of the most tremendous and fastest growing industry (Global Institute of Forensic Research, 2015). For instance, in 2013 alone, Muslim customers consumed US\$46 billion on halal personal care products which is $6.78 \%$ of the global expenditure, and this figure is predicted to increase to US\$73 billion by 2019 , making up over $8.2 \%$ of the global expenditure (State of Global Islamic Economy Report, 2014). In the local scene, halal personal care products contribute 10 to 20 per cent of the local personal care products market (GIFR, 2015). As of third quarter of 2015, Malaysia's export value for halal personal care products stood at RM1.7 billion, reflecting 5.5 per cent of the total halal exports which is valued at RM31.1 billion (Ministry of International Trade and Industry, 2015). However, in a world that is becoming more spiritually conscious, the acceptance and awareness level towards halal personal care products is still low within the Muslim community (Hunter, 2012). For instance, a report by World Halal Forum (2011) revealed that the customers' level of awareness and understanding towards halal personal care products in Saudi Arabia and United Arab Emirates (UAE) was comparatively low at 18-30 per cent as compared to halal meat and meat-based products and halal food which was estimated at 94-98 per cent and 40-64 per cent respectively. In the local front, a study by Halal Development Corporations (2014) also found that the customers' acceptance and awareness towards halal personal care products in Malaysia was comparatively low. For instance, both Muslim and non-Muslims in Malaysia are familiar and aware with the concept of halal foods products but the term halal personal care products are relatively new even for Muslim consumers (Rahim, Shafii and Shahwan, 2013). Due to their lack of awareness and understanding on this halal concept, Muslim customers in Malaysia, therefore, have turned to conventional and imported brands whose halal status and safety issues are questionable and doubtful (Mokhtar, Nooreha \& Nik Mustapha, 2012). It seems that the local halal personal care products have yet to become a "household brand" for Muslim customers in Malaysia (Hashim and Musa, 2013). Therefore, it is essential to explore and identify what are the factors that may actually influence the customers' behavioral intention to purchase halal personal care products. On a different note, it has been found that the customers' behavior study on halal products especially on halal non-food segments is very scarce and limited (Rahim et al., 2013; Rahman, Asrarhaghighi and Rahman, 2015). For example, in their study to investigate the awareness and perception of Muslim consumers on halal cosmetics and personal care products, Rahim, Shafii \& Shahwan (2015) found that very limited number of studies have been conducted on halal non-food segments compared to halal food and Islamic financial services. Similarly, a study by Swidi, Wie, Hassan, AlHosam and Mohd Kassim (2010) on the emergence, growth, and prospects of halal cosmetics in Malaysia revealed that among the three main sectors of halal industry (i.e. food, non-food, and financial service sectors), halal non-food sector is one of the less researched areas in halal industry that needs to be explored and investigated further. Therefore, this study shall attempt to provide an interesting platform to unravel the customer behavior research on halal personal care products, thus, providing a significant contribution to the body of knowledge and literature on halal non-food studies.

Theoretically speaking, this study further extends the purchase intention research on halal personal care products by applying the decomposed theory of planned behavior (DTPB) as the underpinning theory of the study. By decomposing the attitudinal, normative, and perceived control beliefs into 
relevant multidimensional constructs, the researcher expects to have a higher explanatory power and a more precise understandings of the antecedents or determinants of behavior. In fact, most of the purchase intention studies on halal personal care products emphasize on the main construct of Ajzen's (1991) theory of planned behavior (TPB) as the main factors that will affect one's purchase intention and they seemed to ignore the importance of the antecedents or determinants of attitude, subjective norm, and perceived behavioral control in predicting the customers' behavioral intentions. Therefore, this study attempts to close this theoretical gap by incorporating the relevant antecedents of attitude, subjective norm, and perceived behavioral control in DTPB model as a new approach in predicting customers' behavioral intention in the context of halal personal care products.

\section{METHODOLOGY}

The target population of this study was all Muslim respondents over the age of 20 to 60 years old at six major cities in Klang Valley namely Kuala Lumpur, Klang, Kajang, Subang Jaya, Petaling Jaya and Shah Alam. Based on the natures and objectives of the research, the present study used a combination of purposive and quota sampling in choosing the appropriate respondents for the study. These two sampling techniques were utilized so as to provide findings of a higher degree of accuracy and generalizability. With regards to the sample size, the researcher referred to the sample size as recommended by Israel (1992) whose calculation was based on the Precision Levels where the Confidence Level is $95 \%$ and $P=0.5$. According to Israel (1992), a sample size for a population of more than one hundred thousand with precision level of $\pm 5 \%$ is 400 observations. This provides the researcher with a sample size that exceeded the minimum sample size as recommended by most researchers (Bentler and Chou, 1987; Ding, Velicer and Harlow, 1995; Hair, Anderson, Tatham and Black, 1998; Kelloway, 1998; Shah and Goldstein, 2006). To avoid biases and possibility of unreturned questionnaires, 450 questionnaires were distributed at the identified locations.

In this study, a self-administered questionnaire were used as the main research instrument. The advantages of self-administered questionnaire is that it can provide high response rates, reduce the missing data, and shorten the data collection period (Brace, 2008). Meanwhile, a 10-point Likert scale, ranging from 1 to 10 where 1 denotes "strongly disagree", 2 for "disagree", 3 for "moderately disagree", 4 for "slightly disagree", 5 for "mildly disagree", 6 for "mildly agree", 7 for "slightly agree", 8 for "moderately agree", 9 for "agree", and 10 for "strongly agree", were used to measure the proposed constructs in this study. Items used to measure subjective norm were adapted from the scale used by Husin, Ismail \& Rahman (2016). In addition, items used to measure friends' influences and family members' influences were adapted from the instruments used by Khalid \& John (2008) while, items used to measure purchase intention were generated based on the work of Rahman et al. (2015) and Haque, Sarwar, Farzana, Tarofder \& Hossain (2015). The data were later analyzed using the Statistical Package for Social Sciences (SPSS) and Partial Least Square - Structural Equation Modeling (PLS SEM).

\section{RESULTS}

A total of 450 copies of the questionnaires were distributed to the respondents. Out of the 450 copies, 430 copies were returned and only 405 copies could be used for further analysis, thus, yielding a response rate of 90 per cent. 
INTERNATIONAL JOURNAL OF ACADEMIC RESEARCH IN BUSINESS AND SOCIAL SCIENCES

Vol. 8, No. 11, Nov, 2018, E-ISSN: 2222-6990 (C) 2018 HRMARS

\section{Measurement Model Analysis}

To assess the measurement model, two types of validity were examined namely convergent validity and discriminant validity.

\section{Convergent Validity}

Convergent validity is the degree to which a measure correlates positively with another measures of the same construct (Chin, 2010; Ramayah and Rahbar, 2013). Establishing convergent validity involves satisfying the conditions imposed upon indicators' loadings, composite reliability, and the average variance extracted (AVE) (Lee and Kozar, 2008). Based on an established rule of thumbs, the indicators' loadings of an item should exceed the threshold value of 0.60 (Chin, 1998; Gholami, Sulaiman, Ramayah and Molla, 2013), while, the cut-off point for both the composite reliability and AVE is 0.70 and 0.50 respectively (Hair, Tomas, Ringle and Sarstedt, 2017). The following Table 1 summarizes the indicators' loadings, AVE and composite reliability of all the constructs in this study.

Table 1 : Convergent validity

\begin{tabular}{lllll}
\hline Constructs & Items & Loadings & AVE $^{\mathrm{a}}$ & $\mathrm{CR}^{\mathrm{b}}$ \\
\hline Friends' & EF1 & 0.738 & 0.679 & 0.894 \\
Influences & EF2 & 0.819 & & \\
& EF3 & 0.856 & & \\
\hline Family's & EF4 & 0.876 & & \\
Influences & FM1 & 0.825 & 0.784 & 0.936 \\
& FM2 & 0.899 & & \\
\hline Subjective Norm & FM & 0.914 & & \\
& FM4 & 0.903 & & \\
& SN1 & 0.759 & 0.775 & 0.945 \\
& SN2 & 0.891 & & \\
& SN3 & 0.917 & & \\
& SN4 & 0.885 & & \\
& SN5 & 0.938 & & \\
\hline Intention to & ITP1 & 0.732 & 0.625 & 0.909 \\
& ITP2 & 0.784 & & \\
& ITP3 & 0.777 & & \\
& ITP4 & 0.855 & & \\
\hline & ITP5 & 0.805 & & \\
\hline ITP6 & 0.786 & & \\
\hline
\end{tabular}

Based on Table 1, all the indicators' loadings, AVE, and composite reliability for all the constructs under study surpass the $0.60,0.50$ and 0.70 respectively, thus, fulfilling all the three criterions of convergent validity.

\section{Discriminant Validity}

The second criterion to be fulfilled for the measurement model analysis is to evaluate the discriminant validity of the indicators. Discriminant validity is the degree to which a construct is truly 
INTERNATIONAL JOURNAL OF ACADEMIC RESEARCH IN BUSINESS AND SOCIAL SCIENCES

Vol. 8, No. 11, Nov, 2018, E-ISSN: 2222-6990 @ 2018 HRMARS

different from other constructs in the model. In this study, the cross-loadings analysis, Fornell-Larcker criterion analysis and Heterotrait-Monotrait (HTMT) criterion analysis will be used to measure the discriminant validity (Hair et al., 2017). Specifically, an indicators' loading on the associated construct should be greater than any of its cross-loadings (i.e. its correlation) on other constructs (Hair et al., 2017). Based on Table 2, the indicators' loadings on the associated construct (bolded) are all greater than its cross-loadings on other constructs, thus, indicating an adequate level of discriminant validity.

Table 2 : Cross Loadings

\begin{tabular}{lcccc}
\hline & Family & Friend & ITP & SN \\
\hline Friend1 & 0.22 & $\mathbf{0 . 7 3 8}$ & -0.084 & 0.157 \\
Friend2 & 0.463 & $\mathbf{0 . 8 1 9}$ & 0.24 & 0.33 \\
Friend3 & 0.433 & $\mathbf{0 . 8 5 6}$ & 0.176 & 0.313 \\
Friend4 & 0.526 & $\mathbf{0 . 8 7 6}$ & 0.274 & 0.377 \\
Family1 & $\mathbf{0 . 8 2 5}$ & 0.573 & 0.311 & 0.434 \\
Family2 & $\mathbf{0 . 8 9 9}$ & 0.405 & 0.499 & 0.464 \\
Family3 & $\mathbf{0 . 9 1 4}$ & 0.447 & 0.449 & 0.554 \\
Family4 & $\mathbf{0 . 9 0 3}$ & 0.466 & 0.447 & 0.522 \\
ITP1 & 0.239 & 0.134 & $\mathbf{0 . 7 3 2}$ & 0.303 \\
ITP2 & 0.334 & 0.142 & $\mathbf{0 . 7 8 4}$ & 0.329 \\
ITP3 & 0.404 & 0.204 & $\mathbf{0 . 7 7 7}$ & 0.394 \\
ITP4 & 0.437 & 0.167 & $\mathbf{0 . 8 5 5}$ & 0.392 \\
ITP5 & 0.447 & 0.213 & $\mathbf{0 . 8 0 5}$ & 0.359 \\
ITP6 & 0.409 & 0.215 & $\mathbf{0 . 7 8 6}$ & 0.378 \\
SN1 & 0.319 & 0.351 & 0.218 & $\mathbf{0 . 7 5 9}$ \\
SN2 & 0.512 & 0.31 & 0.4 & $\mathbf{0 . 8 9 1}$ \\
SN3 & 0.497 & 0.33 & 0.432 & $\mathbf{0 . 9 1 7}$ \\
SN4 & 0.574 & 0.365 & 0.458 & $\mathbf{0 . 8 8 5}$ \\
SN5 & 0.513 & 0.33 & 0.438 & $\mathbf{0 . 9 3 8}$ \\
\hline
\end{tabular}

Next, the discriminant validity of the measurement model was tested using the criteria suggested by Fornell and Larcker (1981). Specifically, this criteria requires that the square root of each construct's AVE should be greater than its highest correlation with any other construct (Hair et al., 2017). Based on Table 3, the square root of AVE (bolded) are all greater than the off-diagonal elements in their corresponding row and column, thus, suggesting a sufficient level of discriminant validity.

Table 3 : Fornell-Larcker Criterion

\begin{tabular}{lcccc}
\hline & 1 & 2 & 3 & 4 \\
\hline 1. Family & $\mathbf{0 . 8 8 6}$ & & & \\
2. Friends & 0.529 & $\mathbf{0 . 8 2 4}$ & & \\
3. ITP & 0.484 & 0.228 & $\mathbf{0 . 7 9 1}$ & \\
4. SN & 0.561 & 0.379 & 0.456 & $\mathbf{0 . 8 8}$ \\
\hline
\end{tabular}


The final criterion to establish discriminant validity of the measurement model is through HTMT criterion analysis, a more advanced method of detecting discriminant validity (Henseler, Ringle and Sarstedt, 2015). Henseler et al. (2015) suggest a threshold value of 0.90 if the path model includes the constructs that are very conceptually very similar. However, when the constructs in the path model are theoretically more distinct, a lower thresholds value of 0.85 is acceptable. This study followed the latter since the path model in this study was theoretically more different. Table 4 shows that all the HTMT values in this study were less than the cut-off point of 0.85 , thus, suggesting an acceptable level of discriminant validity.

Table 4 : Heterotrait-Monotrait (HTMT) Criterion

\begin{tabular}{lcccc}
\hline & 1 & 2 & 3 & 4 \\
\hline 1. Family & 0.648 & & & \\
2. Friends & 0.324 & 0.571 & & \\
3. ITP & 0.702 & 0.532 & 0.269 & \\
4. SN & 0.594 & 0.408 & 0.488 & \\
\hline
\end{tabular}

In total, the measurement model in this study demonstrates both the convergent validity and discriminant validity, thus, permitting the researcher to proceed with the structural model analysis.

\section{Structural Model Analysis}

Assessing the structural model involves evaluating $R^{2}$, beta and the corresponding $t$-values (Hair, Hult, Ringle and Sarstedt, 2014). To obtain the t-values, a bootstrapping procedure with 1000 resamples was applied (Chin, 1998). In addition, researchers should also report predictive relevance $\left(Q^{2}\right)$ and effect sizes $\left(f^{2}\right)$ (Hair et al., 2014; Ramayah, Mohamad, Omar, Marimuthu and Yeap, 2013). The results of the structural model analysis in this study is shown in Table 5.

Table 5 : Results of the Structural Model Analysis

\begin{tabular}{lllllllll}
\hline Hypo & Relationships & $\begin{array}{l}\text { Std } \\
\text { Beta }\end{array}$ & $\begin{array}{l}\text { Std } \\
\text { Error }\end{array}$ & t-value & $\mathrm{R}^{2}$ & $\mathrm{f}^{2}$ & $\mathrm{Q}^{2}$ & \\
\hline H1 & SN --> ITP & 0.097 & 0.051 & 1.887 & 0.209 & 0.012 & 0.281 & Supported \\
H2 & EF --> SN & 0.114 & 0.048 & 2.368 & 0.324 & 0.014 & 0.227 & Supported \\
H3 & FM --> SN & 0.500 & 0.045 & 11.193 & & 0.267 & & Supported
\end{tabular}

First, one needs to look at the antecedents of subjective norm. Friends' influence $(\beta=0.114, t=2.368$, $p<0.10)$ and family members' influence $(\beta=0.500, t=11.193 p<0.10)$ both had a positive effect on subjective norm, thus, giving support for $\mathrm{H} 2$ and $\mathrm{H} 3$. These two constructs explained 32.4 per cent of the variance in subjective norm and based on the suggestion of Chin (1998), this $R^{2}$ value can be considered weak. Surprisingly, family members' influence was the strongest predictor of subjective norm with a beta value of 0.500 .

Next, one needs to look at the predictor of intention to purchase. Subjective norm $(\beta=0.097, t=$ $1.887, \mathrm{p}<0.10$ ) had a positive impact on intention to purchase, thus, providing support for $\mathrm{H} 1$. This 
particular construct explained only 20.9 per cent of the variance in purchase intention and based on the suggestion of Chin (1998), this $\mathrm{R}^{2}$ value can be considered weak.

Subsequently, one needs to assess the effect sizes $\left(f^{2}\right)$. As asserted by Sullivan \& Feinn (2012), "While a $P$ value can inform the reader whether an effect exists, the $P$ value will not reveal the size of the effect. In reporting and interpreting studies, both the substantive significance (effect size) and statistical significance (P value) are essential results to be reported" (p.279). In assessing effect sizes, Hair et al. (2014) suggested that the change in the $R^{2}$ value should also be examined. The method suggested is to examine the $R^{2}$ change when a specified exogenous construct is omitted from the model. This is to evaluate whether the omitted construct has a substantive impact on the endogenous construct. To measure the magnitude of the effect size, the researcher used Cohen's (1988) guideline which is $0.02,0.15$, and 0.35 , representing small, medium, and large effects respectively. Looking at the $f^{2}$ values in Table 5 , it can be observed that all the relationships showed substantive impact whereby there were 2 relationships with small effect sizes and 1 with medium effect sizes.

Finally, it is also important to measure the predictive relevance of the model by using the blindfolding procedure (Hair et al., 2014). Blindfolding is a sample reuse technique that omits every dth data point in the endogenous construct's indicators and estimates the parameters with the remaining data points (Chin, 1998; Henseler, Ringle and Sinkovics, 2009). Hair et al. (2014) suggested that the blindfolding procedure should only be applied to endogenous constructs that have a reflective measurement (multiple items or single item). If the $Q^{2}$ value is larger than 0 the model has predictive relevance for a certain endogenous construct and otherwise if the value is less than 0 (Fornell and Cha, 1994; Hair et al., 2017). Based on Table 5, it can be seen that all the $Q^{2}$ values are more than 0 ranging from 0.227 to 0.281 , thus, suggesting a sufficient predictive relevance.

\section{DISCUSSION}

Based on Table 5, subjective norm $(\beta=0.097, p<0.10, t=1.887)$ was found to have a positive effect on intention to purchase, thus, giving support to $\mathrm{H} 1$. This result was in line with the findings of other halal-related studies (e.g. Awan, Siddiquei and Haider, 2015; Haque et al., 2015; Hashim and Musa, 2014; Ibrahim and Ismail, 2015). Selectively, in their study to investigate the effect of Generation $Y$ 's religious intensity and assurance on purchase intention toward halal cosmetics and personal care products, Ibrahim and Ismail (2015) found that subjective norm was a significant determinants of behavioral intention. Similarly, based on theory of planned behavior (TPB), Hashim and Musa (2014) revealed that subjective norm has a positive effects on young adult urban Muslim women towards halal cosmetics.

The finding of this study shows that social pressure is an influencing factor in shaping one's behavioral intention to purchase halal personal care products. As postulated by Ajzen (1991) attitudes and beliefs of others in groups to which an individual belongs can shape his or her behavior towards a specific action. Thus, "word of mouth" can be an effective way to create awareness among potential users and at the same time influence their behavioral intention to purchase the products.

Meanwhile, friends' influences $(\beta=0.114, p<0.10, t=2.368)$ and family members' influences $(\beta=$ $0.500, \mathrm{p}<0.10, \mathrm{t}=11.193$ ) was found to have a positive effect on subjective norm, thus, $\mathrm{H} 2$ and $\mathrm{H} 3$ were also supported. This result was consistent with the findings of other information technology and halal financial services studies (Husin and Rahman, 2013; Husin et al., 2016; Khalid and John, 
2008; Parthasarathy and Bhattacherjee, 1998). Selectively, in a conceptual paper to investigate the factors influencing the customers' intention to participate in family takaful scheme, Husin and Rahman (2013) postulated that interpersonal referents such as friends' influences and family members' influences were significant antecedents who may exert social pressure on individuals' intention to participate in family takaful scheme. In a different context, Khalid and John (2008) empirical study on Internet banking acceptance in Malaysia revealed that interpersonal referents (i.e. friends' influences and family members' influences) has a significant positive influence on subjective norm.

These findings suggested that taking these two reference groups into account, more effective advertising and promotional activities can be further developed by marketers and product managers. In addition, this result emphasized the importance of using positive testimonials from these groups because negative word of mouth from them will reduce the customers' acceptance towards the products.

\section{CONCLUSION}

In this study, the researcher adapted DTPB as the underpinning theory of the study in order to provide a better understanding of the factors that influenced one's intention to purchase halal personal care products. None of the purchase intention study on halal personal care products had utilized DTPB as the underpinning theory of their research. This was further supported by Ali, Halim and Ahmad's (2016) study whose findings also revealed that no previous research on halal personal care products has holistically examined the antecedent of attitude, subjective norm, and perceived behavioral control in a single model. Therefore, this study attempts to close this theoretical gap by incorporating the relevant antecedents of attitude, subjective norm, and perceived behavioral control in DTPB model as a new approach in predicting customers' behavioral intention in the context of halal personal care products. Although DTPB was specifically tailored to understand the adoption of information technology (IT), antecedents such as interpersonal referents (i.e. friends' influences and family members' influences), self-efficacy (i.e. self-confidence), and resource-facilitating conditions (i.e. time, money, and information) can still be applied into the research of other natures including that of halal personal care products. Therefore, this study will provide an interesting platform to explore the robustness and rigorousness of the theory in predicting the customers' intention within different research context, thus, improving our understanding of the factors that may influence one's intention to purchase halal personal care products.

\section{REFERENCES}

Ajzen, I. (1991). The theory of planned behaviour. Organizational Behaviour and Human Decision Processes, 50(12), 179-211.

Ali, S., Halim, F., \& Ahmad, N. (2016). The state of halal personal care products research on consumer behaviour: A systematic review of the literature and future research directions. Journal of Marketing Management and Consumer Behavior, 1(4), 40-51.

Awan, H.M., Siddiquei, A.N. \& Haider, Z. (2015). Factors affecting Halal purchase intention-evidence form Pakistan's Halal food sector. Management Research Review, 38(6), 640-660.

Bentler, P.M. \& Chou, C. (1987). Practical issues in structural modelling. Sociological Methods and 
INTERNATIONAL JOURNAL OF ACADEMIC RESEARCH IN BUSINESS AND SOCIAL SCIENCES

Vol. 8, No. 11, Nov, 2018, E-ISSN: 2222-6990 @ 2018 HRMARS

Research, 16(7), 78-117.

Brace, I. (2008). Questionnaire Design: how to plan, structure and write survey material for effective market research, 2nd Edition. Kogan Page Limited, London, UK.

Chin, W. W. (1998). The partial least squares approach to structural equation modeling, in Modern Business Research Methods, Marcoulides, G.A. (Ed). In Lawrence Erlbaum Associates, Mahwah, NJ (pp. 295-336).

Chin, W. W. (2010). How to write up and report PLS analyses. In Esposito Vinzi, V., Chin, W.W., Henseler, J., \& Wang, H. (Eds.), Handbook of partial least squares: Concept, methods and applications. Springer-Verlag, Berlin, Germany.

Cohen, J. (1988). Statistical power analysis for the behavioral sciences. Lawrence Erlbaum, Mahwah, New Jersey.

Ding, L., Velicer, W.F. \& Harlow, L. L. (1995). Effects of estimation methods, number of indicators per factor, and improper solutions on structural equation modelling fit indices. In Structural Equation Modelling (Vol. 2, pp. 119-143).

Fornell, C. \& Larcker, D. F. (1981). Evaluating Structural Equation Models with Unobservable Variables and Measurement Error. Journal of Marketing Research, 18(1), 41-54.

Fornell, C., \& Cha, J. (1994). Partial Least squares. In R.P. Bagozzi (Ed), Advanced methods in marketing research. Cambridge: Blackwell.

Gholami, R., Sulaiman, A.B., Ramayah, T., \& Molla, A. (2013). Senior managers' perception on green information systems (IS) adoption and environmental performance: Results from a field survey. Information \& Management, 50(7), 431-438.

Global Institute of Forensic Research. (2015). The Global Halal Industry: An overview. GIFR. Retrieved from http://www.gifr.net/gifr2013/ch_13.pdf (Retrieved on February 6, 2016)

Hair, J., Anderson, R., Tatham, R. \& Black, W. (1998). Multivariate data analysis. Prentice Hall, Inc, Upper Saddle River, New Jersey.

Hair, J.F., Hult,G.T.M., Ringle, C.M. \& Sarstedt, M. (2014). A Primer on Partial Least Squares Structural Equation Modeling (PLS-SEM). SAGE Publications, Los Angeles, CA.

Hair, J.F., Tomas, G.M.H., Ringle, C.M. \& Sarstedt, M. (2017). A Primer On Partial Least Squares Structural Equation Modeling (PLS-SEM), 2nd Edition. SAGE Publications, California.

Halal Development Corporations. (2014). Opportunities in Halal Economy. HDC, Malaysia, (8th January 2014).

Haque, A., Sarwar, A., Farzana, Y., Tarofder, A.K. \& Hossain, M. A. (2015). Non-Muslim consumers' perception toward purchasing halal food products in Malaysia. Journal of Islamic Marketing, 6(1), 133-147.

Hashim, A.J.C.M. \& Musa, R. (2013). Modelling the effects of the attitude of young adult urban Muslim women towards halal cosmetic products: New insights for championing the halal economy. International Journal of Education and Research, 1(7), 1-8.

Hashim, A.J.C.M. \& Musa, R. (2014). Factors Influencing Attitude towards Halal Cosmetic among Young Adult Urban Muslim Women: A Focus Group Analysis. Procedia-Social and Behavioral Sciences, 130, 129-134.

Henseler, J., Ringle, C.M., \& Sarstedt, M. (2015). A new criterion for assessing discriminant validity in variance-based structural equation modeling. Journal of the Academy of Marketing Science, 
INTERNATIONAL JOURNAL OF ACADEMIC RESEARCH IN BUSINESS AND SOCIAL SCIENCES

Vol. 8, No. 11, Nov, 2018, E-ISSN: 2222-6990 @ 2018 HRMARS

43(13), 115-135.

Henseler, J., Ringle, C.M., \& Sinkovics, R. R. (2009). The use of Partial Least Squares Path Modeling in International Marketing. Advances in International Marketing, 20(8), 277-320.

Hunter, M. (2012). "The emerging Halal cosmetic and personal care market: integrating the organization towards the philosophy of Tawhid." Working Paper, University Malaysia Perlis.

Husin, M.M. \& Rahman, A. A. (2013). What drives consumers to participate into family takaful schemes? A literature review. Journal of Islamic Marketing, 4(3), 264-280.

Husin, M.M., Ismail, N. \& Rahman, A. A. (2016). The roles of mass media, word of mouth and subjective norm in family takaful. Journal of Islamic Marketing, 7(1), 59-73.

Ibrahim, H. \& Ismail, H. (2015). A Generational Cohort Study of the Relationship between Religious Intensity and Religious Assurance for the Purchase of Non-food Products. International Journal of Economics and Financial Issues, 5(4), 330-334.

Israel, G. D. (1992). Determining sample size. University of Florida Cooperative Extension Service, Institute of Food and Agriculture Sciences, EDIS. Retrieved from http://www.edis.ifas.ufl.edu/pdffiles/PD/PD00600.pdf (Retrieved on August 2, 2016)

Kelloway, E. K. (1998). Using Lisrel for structural equation modelling. International Educational and Professional Publisher, SAGE Publications, CA.

Khalid, M.N. \& John, M. P. (2008). An exploratory study into the adoption of internet banking in a developing country: Malaysia. Journal of Internet Commerce, 7(4), 29-73.

Lee, Y., \& Kozar, K. (2008). An empirical investigation of anti-spyware software adoption: a multitheoretical perspective. Information \& Management, 45(2), 109-119.

Ministry of International Trade and Industry. (2015). Exports of Halal Cosmetic and Personal Care Products Hit RM1.7 Billion, Emerging as the Fastest Growing Consumer Segment. MITI, Malaysia. Retrieved from http://www.miti.gov.my/index.php/pages/view/3114 (Retrieved on May 5, 2016)

Mokhtar, A., Nooreha, H. \& Nik Mustapha, N. H. (2012). Guidelines for Implementing Value-Based Total Performance Excellence Model in Business Organizations. Presentations at the Islamic Perspective Forum. Manila, Philippines.

Parthasarathy, M. \& Bhattacherjee, A. (1998). Understanding post-adoption behaviour in the context of online services. Information Systems Research, 9(4), 362-379.

Rahim, N.F., Shafii, Z. \& Shahwan, S. (2013). Awareness and Perception of Muslim Consumers on NonFood Halal Product. Journal of Social and Development Sciences, 4(10), 478-487.

Rahim, N.F., Shafii, Z. \& Shahwan, S. (2015). Awareness and Perception of Muslim Consumers on Halal Cosmetics and Personal Care Products. International Journal of Business, Economics and Management, 2(1), 1-14.

Rahman, A.A., Asrarhaghighi, E. \& Rahman, S. A. (2015). Consumers and Halal cosmetic products: knowledge, religiosity, attitude and intention. Journal of Islamic Marketing, 6(1), 148-163.

Ramayah, T., \& Rahbar, E. (2013). Greening the environment through recycling: An empirical study. Management of Environmental Quality: An International Journal, 24(6), 782-801.

Ramayah, T., Mohamad, O., Omar, A., Marimuthu, M., \& Yeap, J. A. L. (2013). Green Manufacturing Practices and Performance among SMEs : Evidence from a Developing Nation. In IGI Global.

Shah, R. \& Goldstein, S. (2006). Use of structural equation modelling in operations management 
research. Journal of Operations Management, 24(2), 148-169.

State of Global Islamic Economy Report. (2014). Halal Products. Retrieved from http://www.dinarstandard.com/state-of-the-global-Islamic-economy-report-2014 (Retrieved on January 25, 2016)

Sullivan, G.M. \& Feinn, R. (2012). Using Effect Size - why the p Value is not Enough. Journal of Graduate Medical Education, 4(3), 279-282.

Swidi, A., Wie, C., Hassan, M.G., Al-Hosam, A. \& Mohd Kassim, A. W. (2010). The Mainstream Cosmetics Industry in Malaysia and the Emergence, Growth and Prospects of Halal Cosmetics. In Proceeding of the Third International Conference on International Studies (ICIS), 1st and 2nd December, 2010, Kuala Lumpur, Malaysia (pp. 1-20).

World Halal Forum. (2011). The 6th World Halal Forum, 4-5 April 2011. Kuala Lumpur, Malaysia, Post Event Report. 